\title{
Muhammad Iqbal's Romanticism of Power: A Post Structural Approach to His Persian Lyrical Poetry. Wiesbaden, Dr. L. Reichert Verlag, 2004, 270 p.
}

\section{Michele Bernardini}

\section{(2) OpenEdition \\ 1 Journals}

Édition électronique

URL : http://journals.openedition.org/abstractairanica/21011

DOI : 10.4000/abstractairanica.21011

ISSN : 1961-960X

Éditeur :

CNRS (UMR 7528 Mondes iraniens et indiens), Éditions de l'IFRI

\section{Édition imprimée}

Date de publication : 15 mai 2007

ISSN : 0240-8910

Référence électronique

Michele Bernardini, « Muhammad Iqbal's Romanticism of Power: A Post Structural Approach to His Persian Lyrical Poetry. Wiesbaden, Dr. L. Reichert Verlag, 2004, 270 p. », Abstracta Iranica [En ligne], Volume 28 | 2007, document 347, mis en ligne le 18 septembre 2007, consulté le 25 septembre 2020 URL : http://journals.openedition.org/abstractairanica/21011 ; DOI : https://doi.org/10.4000/ abstractairanica. 21011

Ce document a été généré automatiquement le 25 septembre 2020.

Tous droits réservés 


\title{
Muhammad Iqbal's Romanticism of Power: A Post Structural Approach to His Persian Lyrical Poetry. Wiesbaden, Dr. L. Reichert Verlag, 2004, 270 p.
}

\author{
Michele Bernardini
}

1 Imposante recherche sur un auteur complexe, Mohammad Eqbāl, qui vécut à une époque d'intenses transformations historiques (1877-1938) et eut une vaste production littéraire en persan - bien que l'A. s'attache surtout au grand succès qu'il eut en Inde, au Pakistan, en Afghanistan et au Tadjikistan, plutôt qu'à celui qu'il connut en Iran.

2 La méthodologie adoptée par Popp, originale et basée sur une analyse "structuraliste » et «post-structuraliste » de la production littéraire d'Eqbāl, est inédite dans les recherches dédiées à la littérature persane. Cette approche permet d'avoir une perception plus riche de l'œuvre de cet auteur qui fut non seulement un subtil connaisseur de la littérature classique persane, en particulier Hâấ, Sa'dī et Rūmī, et du style " indien », mais, en même temps, un interprète de la philosophie occidentale, en particulier du romanticisme, ainsi que de Nietzsche et de Bergson.

3 Une longue introduction trace un cadre méthodologique à travers les travaux du passé comme la Strukturale Textanalyse de Michael Titzmann, les études sémiotiques d'Umberto Eco, la théorie de la littérature de Jurij Lotman, la théorie de la lecture de Wolfgang Iser, Le plaisir du texte de Roland Barthes, l'intertextualité de Gérard Genette. L'A. exclut par contre de son étude les travaux de Jacques Derrida et de Julia Kristeva, qui ne lui paraissent pas fondamentaux pour sa recherche.

4 Dans l'analyse structuraliste de Popp, la distinction principale s'établit entre sens et signification. Il développe un discours sur l'auteur et son message, qui tient compte surtout de l'auto-représentation dans les œuvres d'Eqbāl. Ainsi, par exemple, le chapitre sur le Passionate Lover apparaît comme particulièrement intéressant par le fait 
qu'il aborde d'anciennes questions, telles que celle de l'objet du message : celui-ci étant absent dans certains poèmes, dans d'autres il devrait être identifié avec l'Aimé qui, toutefois, n'est pas toujours explicitement indiqué et, donc, pourrait représenter Dieu. Le rapport entre celui qui parle et celui qui reçoit le message est l'objet d'une attention particulière. Le poète peut parler soit directement avec Dieu - dans ce cas, les auditeurs se limitent à écouter -, mais aussi il peut parler à son propre cœur, et alors c'est luimême qui va écouter son propre message. Popp donne d'autres exemples, comme celui de Dieu qui parle au poète, ou celui des auditeurs qui s'adressent à lui. Dans ce cadre, de véritables tropes littéraires ont une place prépondérante, tels que celui de l'«autoignorance ", celui des « ennemis ", ou encore l'analyse de l'adresse indirecte.

Popp ne manque pas d'aborder des questions techniques: la deuxième partie de l'ouvrage est consacrée aux "Recurring Patterns in Iqbal Poems", et offre un cadre général remarquable du contenu des ouvrages d'Eqbāl. Popp explique la poésie de Eqbāl à l'aide d'un système de paradigmes, souvent liés au romantisme. Ainsi, la question du rapport entre la raison et l'esprit, ou encore celle, très connue, du soi en tant qu'Aimé. Une place importante est destinée à l'émotion et au pouvoir de l'amour. La dernière partie du livre, consacrée à l'imagerie poétique, est très utile pour aborder la personnalité littéraire du poète: on y trouvera la métaphore, la métonymie et l'hyperbole.

\section{INDEX}

Thèmes : 11.1.1. Littérature persane classique

\section{AUTEURS}

MICHELE BERNARDINI

Univresità di Napoli « L'Orientale » 